\title{
Images in Infectious Diseases in Obstetrics and Gynecology
}

Section Editor: David E. Soper, M.D.

\section{Endometrial Tuberculosis}

Abner P. Korn and Susan Ehrlich Department of Obstetrics, Gynecology and Reproductive Sciences, University of California, San Francisco, CA

The images are from a 19-year-old female immigrant from Central America who presented with primary amenorrhea. Pelvic ultrasound (A) shows the presence of intrauterine synechiae vs. septum with punctate calcification. Hysterosalpingogram (B) shows a smoothwalled filling defect within the endometrial cavity and obstructed fallopian tubes. The endometrial cavity was also viewed by hysteroscopy (C). Endometrial biopsy (D) confirmed diagnosis of granulomatous endometritis with presence of rare acid-fast bacilli. The diagnosis of endometrial tuberculosis should be considered in women who present with amenorrhea or infertility, especially if they have lived in "third-world" countries.

(C) 1999 Wiley-Liss, Inc.
A

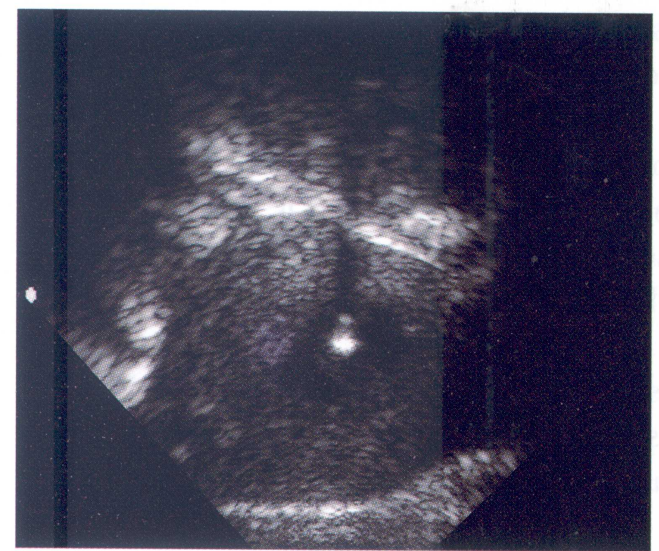

B
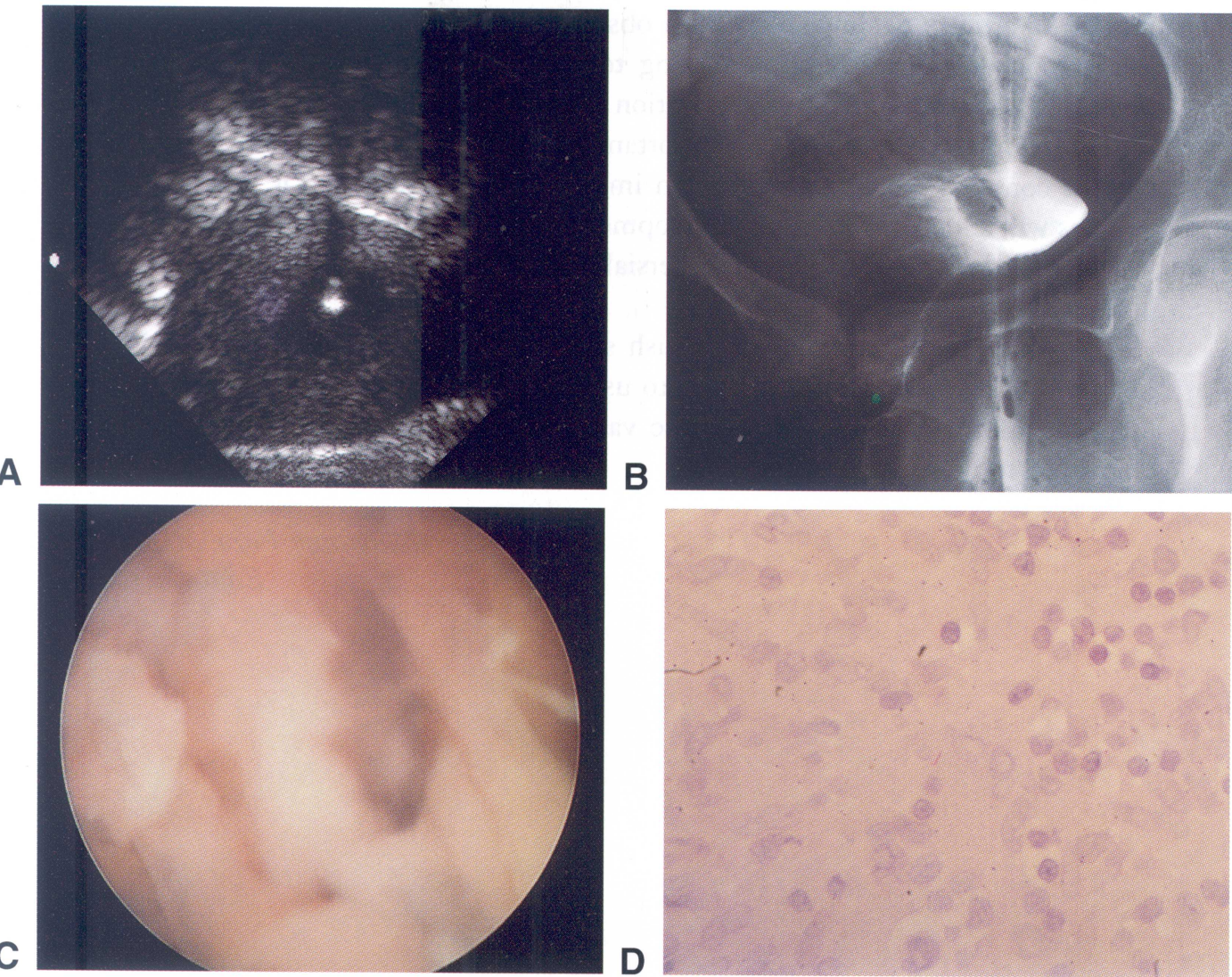

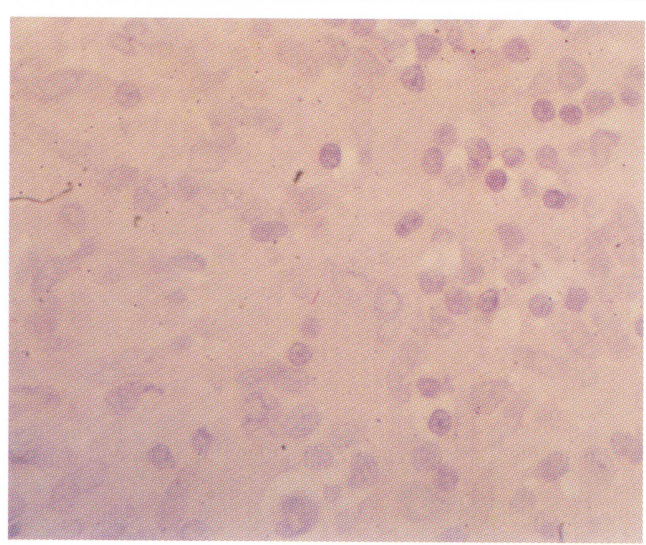

Images in Infectious Diseases in Obstetrics and Gynecology presents clinically important visual images that a practitioner in women's health might encounter. If you have a high-quality color or black-and-white photograph or slide representing such an image that you would like considered for publication, send it with a descriptive legend to Donna Roth, The Woman's Hospital of Texas, 7600 Fannin, Houston, TX 77054.

Images is made possible through an educational grant from 3M Pharmaceuticals. 


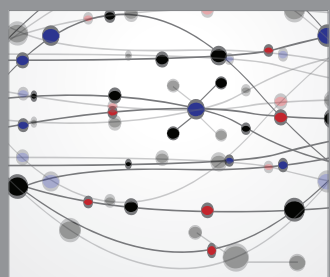

The Scientific World Journal
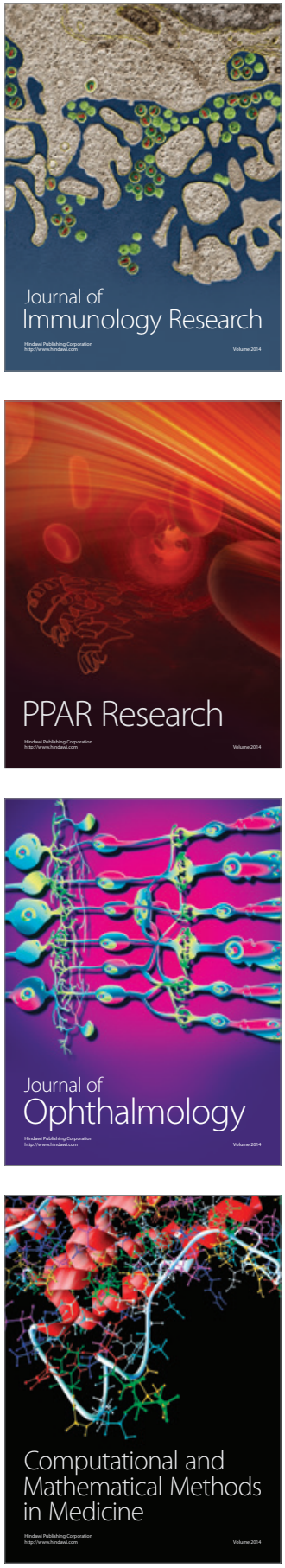

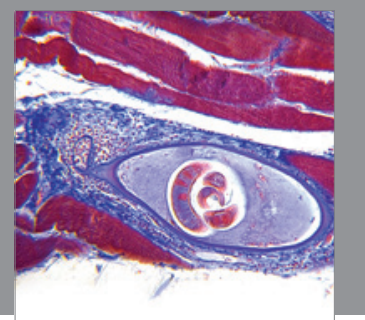

Gastroenterology

Research and Practice
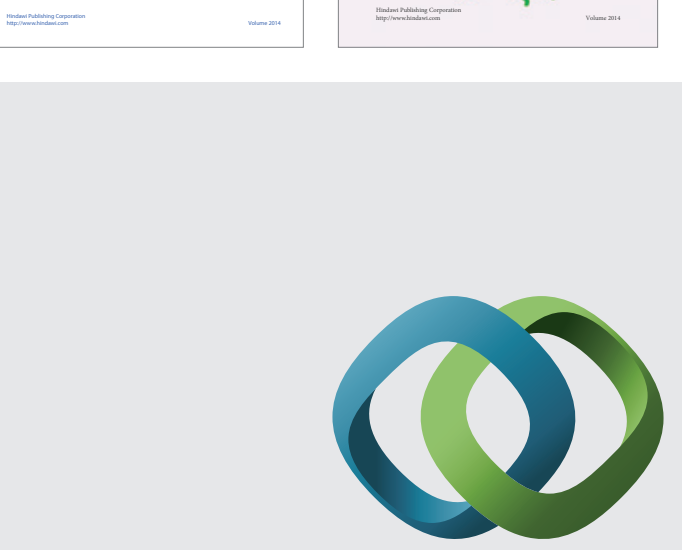

\section{Hindawi}

Submit your manuscripts at

http://www.hindawi.com
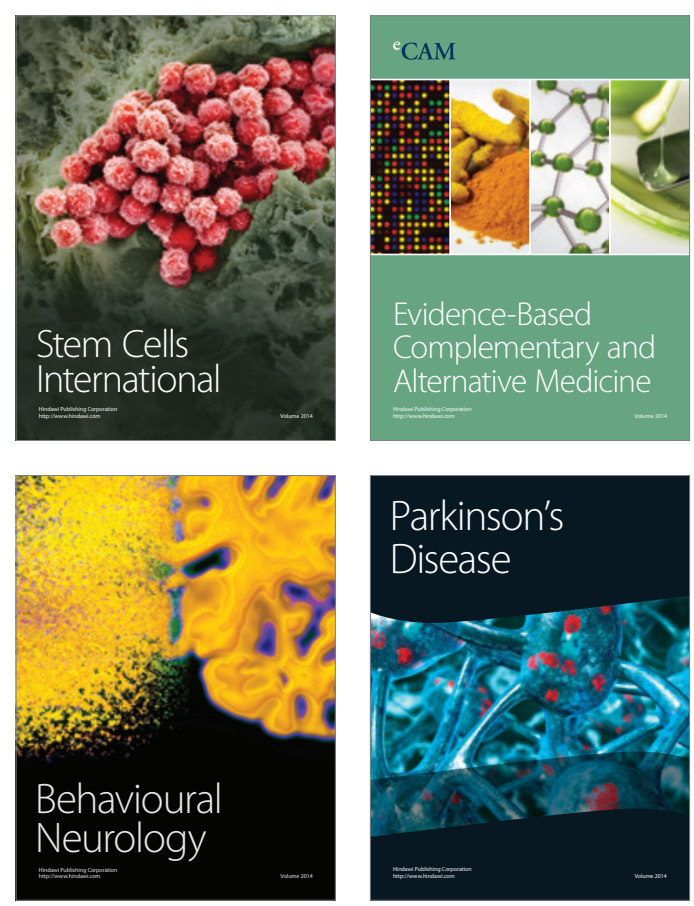

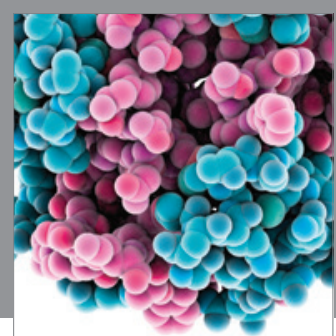

Journal of
Diabetes Research

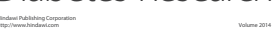

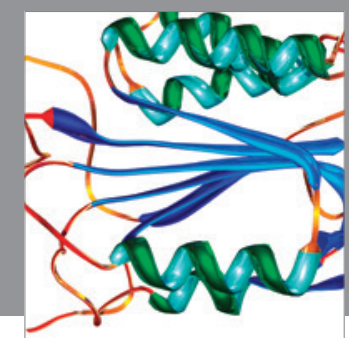

Disease Markers
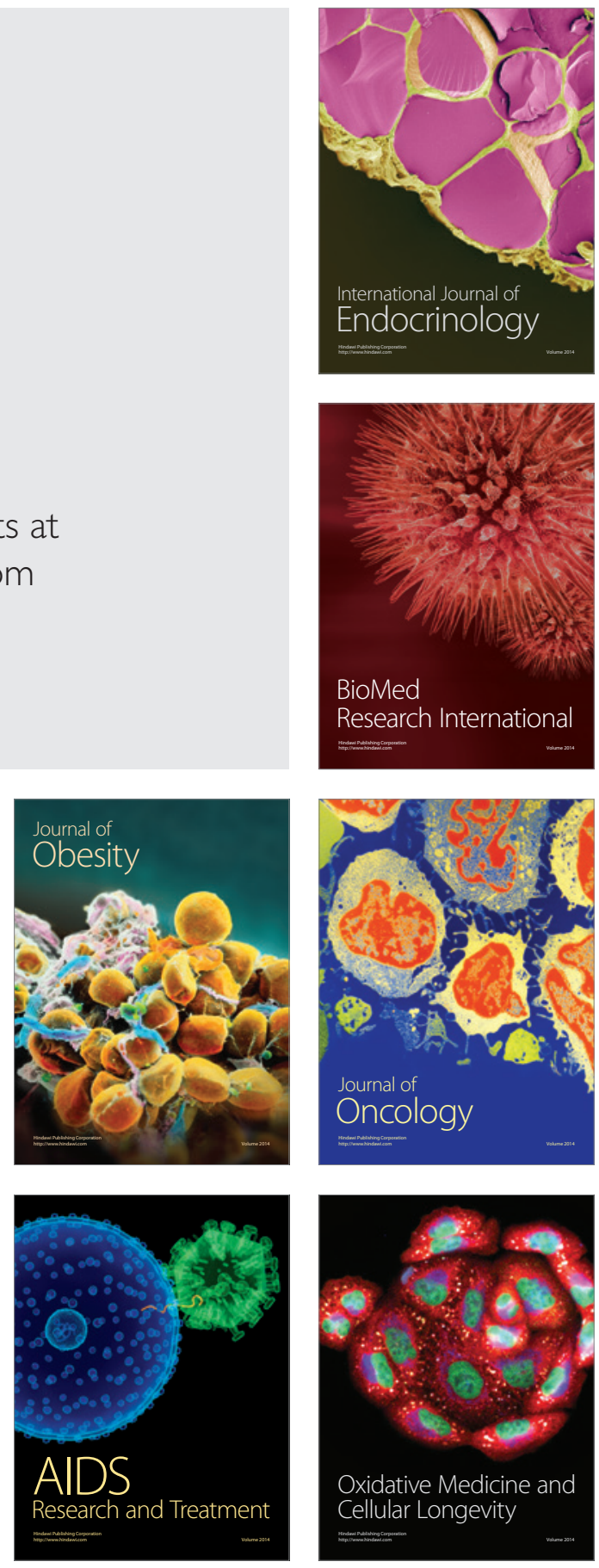